RESEARCH ARTICLE

\title{
Association of Increased Maternal Plasma Homocysteine with the Adverse Birth Outcomes Following Prenatal Psychological Stress
}

\author{
Huiping Zhang ${ }^{1}$, Shaoli Wang ${ }^{2}$, Qian Su ${ }^{1}$, Shan Wang ${ }^{1}$, Dan yao ${ }^{1}$, Shuya Shao ${ }^{1}$, Ding Ding ${ }^{1}$, Zhongliang \\ $\mathrm{zhu}^{3 *}$, Hui $\mathrm{Li}^{1 *}$
}

${ }^{1}$ Department of Neonatology, Xi'an Jiaotong University, China

${ }^{2}$ Department of Obstetrics, Northwestern women's and Children's Hospital, China

${ }^{3}$ Shaanxi Province Biomedicine Key Laboratory, Northwest University, China

*Corresponding author: Hui Li, Department of Neonatology, Xian Jiaotong University, 277 West Yanta Road, Xi'an, Shaanxi 710061, China, Tel: +86-13991232133, Fax: +86-29-8532-3825, E-mail: huili@mail.xjtu.edu.cn;

Zhongliang Zhu, Shaanxi Province Biomedicine Key Laboratory, Northwest University, Xian, Shaanxi 710061, China, Tel: +86-13991-289992, E-mail: zlzhu@mail.xjtu.edu.cn

\begin{abstract}
Objective: Disorders in the expression of plasma homocysteine are significantly related to psychological stress. There is also evidence that prenatal maternal psychological stress could lead to adverse birth outcomes. The present study aimed to determine whether disorders in the expression of plasma homocysteine would be associated with the adverse birth outcomes following prenatal psychological stress (PPS).

Methods: We enrolled 60 pregnancy women with PPS and 60 ones without PPS. The 24-item Hamilton Rating Scale for Depression and the 14-item Hamilton Rating Scale for Anxiety were applied to assess all subjects. The score of depression $\geq$ 20 or the score of anxiety $\geq 14$ was defined as PPS. Maternal plasma homocysteine were measured by enzymatic cycling assay.

Results: Plasma homocysteine were significantly higher in women with PPS than ones without PPS $(27.3 \pm 15.0 \mu \mathrm{mol} / \mathrm{L}$ vs. $20.9 \pm 14.7 \mu \mathrm{mol} / \mathrm{L}, P=0.019)$. Birth weight, birth length, head circumference and gestation length were significantly lower in the infants of women with PPS than ones without PPS $(2849 \pm 740 \mathrm{~g}$ vs. $3212 \pm 578 \mathrm{~g}, P=0.003 ; 48.0 \pm 3.7 \mathrm{~cm}$ vs . $49.3 \pm 2.6 \mathrm{~cm}, P=0.029 ; 32.4 \pm 2.2 \mathrm{~cm}$ vs. $33.4 \pm 1.4 \mathrm{~cm}, P$ $=0.002 ; 37.2 \pm 2.5$ week vs. $38.7 \pm 2.5$ week, $P=0.002)$. Maternal plasma homocysteine negatively and significantly correlated with birth weight, birth length, head circumference and gestation length $(r=-0.621, P<0.001 ; r=-0.604, P<0.001 ; r$ $=-0.669, P<0.001 ; r=-0.760, P<0.001$; respectively).
\end{abstract}

Conclusions: PPS was significantly associated with maternal plasma homocysteine and adverse birth outcomes, and increased maternal plasma homocysteine may be related to the impacts of PPS on poor birth outcomes.

\section{Keywords}

Prenatal psychological stress, Plasma homocysteine, Birth outcomes

\section{Introduction}

It has been shown that prenatal psychological stress (PPS) can result in adverse birth out comes, such as intrauterine growth restriction and preterm birth [1-3]. Several psychosocial stressors, such as death of close relative or husband and other grievous life events could bring about poor birth outcomes [4]. Emerging evidences show that maternal experience of unfortunate life events during or before pregnancy contributes to low birth weight and preterm birth $[5,6]$. However, although a range of psychological physiology theories have been applied to explore the association of PPS and poor birth outcomes, the exact mechanisms still remain unclear.

It is worth noting that psychological stress was significantly related to higher levels of plasma homocysteine [7]. Rodents studies show that plasma Homocysteine significantly increases just after restrained stress $[8,9]$. And both chronic [10] or acute [11,12] psychological stress could result in increased plasma homocysteine levels in human studies.

Moreover, it is reported that elevated maternal Homocysteine levels may be associated with a variety of poor

Citation: Zhang H, Wang S, Su Q, Wang S, yao D, et al. (2017) Association of Increased Maternal Plasma Homocysteine with the Adverse Birth Outcomes Following Prenatal Psychological Stress. Int J Pediatr Res 3:026. doi.org/10.23937/2469-5769/1510026

Received: October 23, 2016: Accepted: March 14, 2017: Published: March 17, 2017

Copyright: (c) 2017 Zhang $\mathrm{H}$, et al. This is an open-access article distributed under the terms of the Creative Commons Attribution License, which permits unrestricted use, distribution, and reproduction in any medium, provided the original author and source are credited. 
birth outcomes, such as intrauterine growth retardation and fetal death [13-18], recurrent early abortion [19] placental abruption [20,21], and severe disorders of blood pressure [22]. Therefore, we hypothesize that plasma homocysteine may be an essential intermediary factor in the relationship between maternal psychological stress and poor birth outcomes. So, the present study was to explore the influences of PPS on maternal plasma homocysteine as well as birth outcomes, and to investigate the relationship between maternal plasma homocysteine and birth outcomes.

\section{Subjects and Methods}

\section{Subjects}

We enrolled 60 pregnant women with PPS in trimester 1 and 60 ones without PPS, aged 23 to 41 years, from northwestern women's and Children's Hospital between January 2014 and August 2015. Exclusion criteria were as follows: any maternal medical illness, hypertension, advanced liver disease, renal failure, cancer, valvular heart disease, heart failure, stroke, atrial fibrillation, peripheral arterial disease, and other severe diseases. The study conformed to the Declaration of Helsinki and the protocol was approved by the Institutional Ethics Committee of northwestern women's and Children's Hospital and written informed consent was obtained from all the subjects.

\section{Maternal and offspring covariates}

Main maternal demographic data, such as age, weight, height and parity, were recorded just after conception. The levels of white blood cells, hemoglobin were assayed by the hospital's clinical laboratory just after conception. Offspring birth weight; birth length, head circumference and gestation length were obtained from the birth records. The subjects were recruited from the hospitalized pregnant women waiting for delivery from the department of gynecology and obstetrics within 37-42 weeks of gestation. Before delivery, participants completed the questionnaire and provided a $2 \mathrm{ml}$ sample of blood to measure total plasma homocysteine.

\section{Definition of PPS}

The 24-item Hamilton Rating Scale for Depression and the 14-item Hamilton Rating Scale for Anxiety were applied to assess all subjects $[23,24]$. The score of depression $\geq 20$ or the score of anxiety $\geq 14$ was defined as PPS.

\section{Total plasma homocysteine measurement}

Venous blood samples were drawn after at last $8 \mathrm{~h}$ of fasting by trained phlebotomists and were collected in EDTA-vacutainer tubes. The plasma samples were centrifuged at $3000 \mathrm{rpm}$ for 20 minutes at $4{ }^{\circ} \mathrm{C}$ and were kept frozen at $-80^{\circ} \mathrm{C}$. Plasma homocysteine was measured by enzymatic cycling assay by the chemistry laboratory of northwestern women's and Children's Hospital. Laboratory technicians who performed these measurements were blind to the clinical characteristics of the study participants.

\section{Statistical analyses}

Data were collected and analyzed with SPSS 13.0 for windows (SPSS Inc., Chicago, IL, USA). Quantitative variables were expressed as mean \pm standard deviation. Kolmogorov-Smirnov test was used to assess normal distribution of quantitative variables. Independent samples t-test was performed to compare the parametric values between the 2 variables. The degree of association between two continuous variables was analyzed using Pearson correlation coefficients. All probability values were two-tailed. A value of $P<0.05$ was considered statistically significant.

\section{Results}

\section{The characteristics at baseline}

The demographic and other clinical characteristics of the subjects were shown in table 1 . The results demonstrated that there were no difference in the main characteristics between the pregnant women with and ones without PPS.

\section{The impacts of PPS on maternal plasma homocysteine}

Figure 1 showed that plasma homocysteine was significantly higher in pregnant women with PPS than ones

Table 1: The characteristics at baseline.

\begin{tabular}{|c|c|c|c|}
\hline Variables & With PPS $(n=60)$ & Without PPS $(n=60)$ & $\mathbf{p}$ \\
\hline Age (years) & $29.1 \pm 4.2$ & $29.5 \pm 4.2$ & 0.619 \\
\hline BMI $\left(\mathrm{kg} / \mathrm{m}^{2}\right)$ & $22.1 \pm 1.2$ & $21.9 \pm 1.3$ & 0.258 \\
\hline WBC $\left(\times 10^{9} / L\right)$ & $8.2 \pm 1.1$ & $8.1 \pm 1.3$ & 0.742 \\
\hline Hemoglobin (g/L) & $124.4 \pm 7.6$ & $126.7 \pm 13.0$ & 0.246 \\
\hline $\mathrm{SBP}(\mathrm{mmHg})$ & $98.2 \pm 5.7$ & $97.8 \pm 5.6$ & 0.736 \\
\hline $\mathrm{DBP}(\mathrm{mmHg})$ & $62.4 \pm 2.2$ & $63.1 \pm 2.7$ & 0.136 \\
\hline TG (mmol/L) & $1.6 \pm 0.72$ & $1.7 \pm 0.65$ & 0.342 \\
\hline $\mathrm{TC}(\mathrm{mmol} / \mathrm{L})$ & $5.2 \pm 0.83$ & $5.0 \pm 0.76$ & 0.247 \\
\hline LDL-C (mmol/L) & $2.3 \pm 0.54$ & $2.2 \pm 0.63$ & 0.153 \\
\hline HDL-C (mmol/L) & $1.1 \pm 0.23$ & $1.0 \pm 0.25$ & 0.235 \\
\hline Glucose (mmol/L) & $5.3 \pm 0.54$ & $5.4 \pm 0.43$ & 0.573 \\
\hline Creatinine (mmol/L) & $61.5 \pm 15.7$ & $59.8 \pm 17.5$ & 0.248 \\
\hline
\end{tabular}

PPS: Prenatal Psychological Stress; BMI: Body Mass Index; WBC: White Blood Cells; SBP: Systolic Blood Pressure; DBP: Diastolic Blood Pressure; TG: Triglyceride; TC: Total Cholesterol; LDL-C: Low Density Lipoprotein Cholesterol; HDL-C: High Density Lipoprotein Cholesterol. 


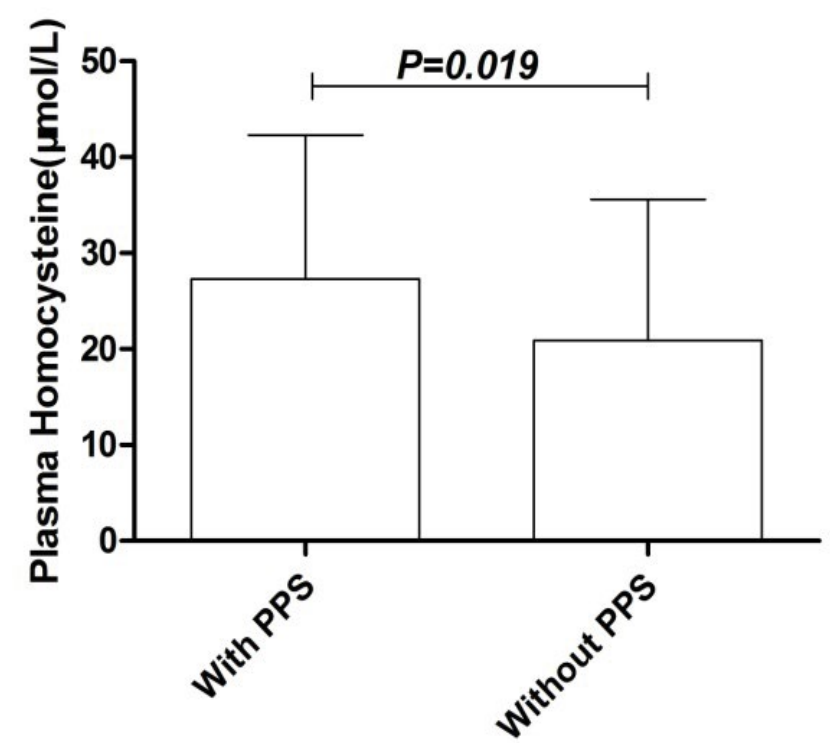

Figure 1: The impacts of PPS on maternal plasma homocysteine in pregnancy.

Plasma homocysteine was significantly higher in pregnant women with PPS than ones without PPS $(27.3 \pm 15.0 \mu \mathrm{mol} / \mathrm{L}$ vs. $20.9 \pm 14.7 \mu \mathrm{mol} / \mathrm{L}, P=0.019$ ). without PPS $(27.3 \pm 15.0 \mu \mathrm{mol} / \mathrm{L}$ vs. $20.9 \pm 14.7 \mu \mathrm{mol} / \mathrm{L}$, $P=0.019)$.

\section{The impacts of PPS on birth outcomes at delivery}

As shown in table 2, compared with the off-springs of women without PPS, birth weight, birth length and head circumference were significantly lower in the off-springs of women with PPS $(2849 \pm 740 \mathrm{~g}$ vs. $3212 \pm 578 \mathrm{~g}, P=0.003$; $48.0 \pm 3.7 \mathrm{~cm}$ vs. $49.3 \pm 2.6 \mathrm{~cm}, P=0.029 ; 32.4 \pm 2.2 \mathrm{~cm}$ vs. $33.4 \pm 1.4 \mathrm{~cm}, P=0.002)$. Gestation length of PPS women was notably shorter than that of women without PPS (37.2 \pm 2.5 week vs. $38.7 \pm 2.5$ week, $P=0.002$; Table 2 ).

\section{The association of maternal plasma homocysteine} with birth outcomes at delivery

As shown in figure 2, maternal plasma homocysteine negatively and significantly correlated with birth weight, birth length and head circumference (Figure 2A, $r=-0.621$, $P<0.001$; Figure 2B, $r=-0.604, P<0.001$; Figure $2 \mathrm{C}, \mathrm{r}=$ $-0.669, P<0.001$, respectively). And gestation length was also negatively and strongly associated with maternal plasma homocysteine (Figure 2D, $r=-0.760, P<0.001$ ).
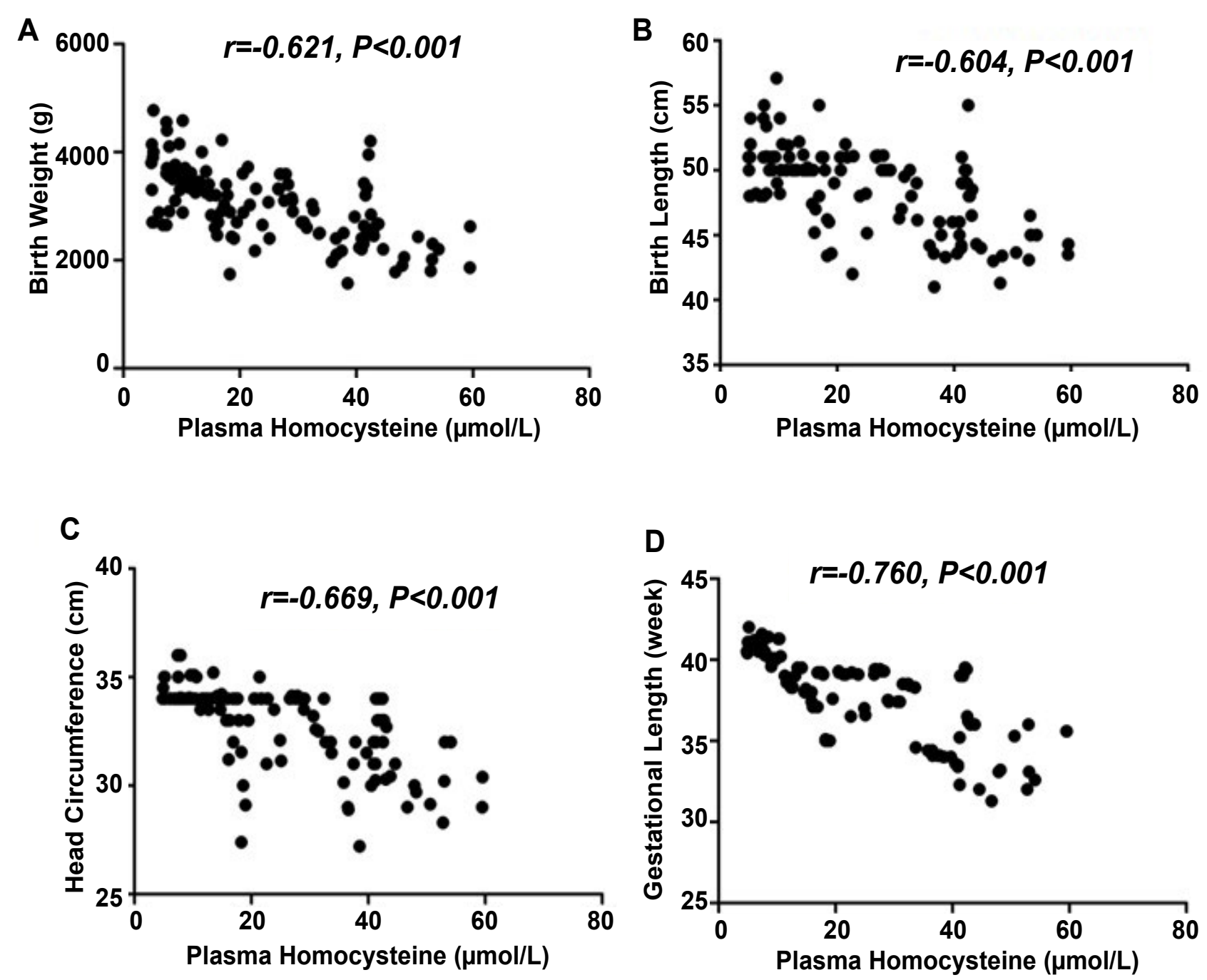

Figure 2: Maternal plasma homocysteine negatively and significantly associated with birth weight, birth length, head circumference and gestation length (Figure 2A, $r=-0.621, P<0.001$; Figure 2B, $r=-0.604, P<0.001$; Figure 2C, $r=$ $-0.669, P<0.001 ; r=-0.760, P<0.001$; respectively). 
Table 2: Comparison of birth outcomes at delivery between pregnant women with PPS and without PPS.

\begin{tabular}{|c|c|c|c|}
\hline Variables & With PPS $(n=6)$ & Without PPS $(n=60)$ & $\mathbf{P}$ \\
\hline Birth weight (g) & $2849 \pm 740$ & $3212 \pm 578$ & 0.003 \\
\hline Birth length (cm) & $48.0 \pm 3.7$ & $49.3 \pm 2.6$ & 0.029 \\
\hline Head circumference $(\mathrm{cm})$ & $32.4 \pm 2.2$ & $33.4 \pm 1.4$ & 0.002 \\
\hline Gestation length (week) & $37.2 \pm 2.5$ & $38.7 \pm 2.5$ & 0.002 \\
\hline
\end{tabular}

\section{Discussion}

The present study explored the impacts of PPS on maternal plasma homocysteine and birth outcomes, and further investigated the relationship between maternal plasma homocysteine and birth outcome. The results demonstrated that PPS exerted notable influences on maternal plasma homocysteine and birth outcomes, and found that maternal plasma homocysteine was negatively and significantly associated with birth outcomes.

It is well known that psychological stress is significantly correlated with the incidence of pathological birth outcomes, such as prematurity and low birth weight [1-3]. So, PPS and its influences on off-springs development and health increasingly attract interest for clinicians and researchers [25-27]. Notably, the retrospective and prospective studies highlight, in a more consistent way, that maternal exposure to calamitous life events in pregnancy is significantly associated with adverse birth outcomes $[5,6]$. In line with previous reports, the present study demonstrated that birth weight; birth length and head circumference of the off springs was considerably influenced by maternal PPS. Some experts have been making efforts to explore, so far, however, the mechanism by which PPS exerts impacts on off springs development still remains poorly understood.

Although it is not clear if hyperhomocysteinemia is a result or a cause of depression induced by stress, many clinical and animal studies indicated that the accumulation of homocysteine has been implicated in the pathogenesis of depression and the increased homocysteine concentration in the plasma might be the result of stress-induced depression [28]. Notably, some reports showed that psychological stress could significantly contribute to high levels of plasma homocysteine [7]. Both animals and population-based studies show that chronic or acute psychological stress could result in increased plasma homocysteine levels [9-12]. Similarly, the present study showed that psychological stress in pregnancy is significantly related to elevated maternal plasma homocysteine levels.

And, some reports show that high plasma homocysteine in pregnancy is related to a range of abnormal birth outcomes, such as fetus growth retardation and preterm birth [15-18]. As a result, we are prompt to further investigate the relationship between maternal plasma homocysteine and infants growth. The results showed that maternal plasma homocysteine was negatively associated with birth weight, birth length and head circumference. The underlying mechanisms by which elevated plasma homocysteine is signifi- cantly related to poor birth outcomes keep unclear. Maternal high homocysteine could cause endothelial dysfunction $[29,30]$ and is positively and significantly associated with blood pressure disorders in subjects with [31] and without hypertension [32]. In pregnant women with blood pressure disorders, poor birth outcomes may result from adverse remodeling of spiral arteries and poor utero placental blood supply, resulting in decreased provision of oxygen and nutrients to the developing fetus [33]. It has been also reported that the endothelium plays an important role in the placentation and fetus development [34]. Therefore, the disorders of blood pressure and endothelial dysfunction may be a link between elevated maternal plasma homocysteine and poor birth outcomes. In addition, elevated homocysteinemia has been implicated in several neurological and psychological disorders [35]. Homocysteine has been associated with cognitive dysfunctions. Blaise, Nédélec's study showed that accumulation of Homocysteine with concomitant apoptosis in selective brain areas and persistently alters neurobehavioral capacities in developing rats [36]. Furthermore, maternal hyper homocysteinemia could be related to congenital malformations of fetal brain resulting from oxidative stress and neural tissue injury [37]. Neurotoxic effects of increased homocysteine levels during pregnancy, like reduced expressions of glial fibrillary acidic protein and S100B protein and increased DNA fragmentation and p53 mRNA expression in the brain of pup's rats, may elevate developmental risk on fetal brain structure and function. Homocysteine could result in direct neurotoxicity by over stimulating the $\mathrm{N}$-methyl-Daspartate (NMDA) subtype of glutamate receptor [38]. Excessive stimulation of these receptors was associated with the neurotoxic response in the brain. Moreover, elevation of cellular Homocysteine level may contribute to oxidative stress, increases maxi calcium-activated potassium channel activity, and decreases exocytosis of secretory granules, which is involved in the developmental impairments and neurotoxicity [39].

In conclusion, PPS is associated with increased maternal plasma homocysteine and poor birth outcomes, and maternal increased plasma homocysteine may be related to the impacts of PPS on poor birth outcomes.

\section{Acknowledgments}

The work was funded by the science research project of the key laboratory in Education Department of Shaanxi Provincial Government in China (No. 14JS108).

\section{References}

1. Berkowitz GS, Kasl SV (1983) The role of psychosocial factors in spontaneous preterm delivery. J Psychosom Res 27: $283-290$ 
2. Bolten MI, Wurmser H, Buske-Kirschbaum A, Papousek M, Pirke KM, et al. (2011) Cortisol levels in pregnancy as a psychobiological predictor for birth weight. Arch Womens Ment Health 14: 33-41.

3. Class QA, Lichtenstein P, Langstrom N, D'Onofrio BM (2011) Timing of prenatal maternal exposure to severe life events and adverse pregnancy outcomes: a population study of 2.6 million pregnancies. Psychosom Med 73: 234-241.

4. Khashan AS, McNamee R, Abel KM, Mortensen PB, Kenny LC, et al. (2009) Rates of preterm birth following antenatal maternal exposure to severe life events: a populationbased cohort study. Hum Reprod 24: 429-437.

5. Khashan AS, McNamee R, Abel KM, Pedersen MG, Webb $\mathrm{RT}$, et al. (2008) Reduced infant birth weight consequent upon maternal exposure to severe life events. Psychosom Med 70: 688-694.

6. Precht DH, Andersen PK, Olsen J (2007) Severe life events and impaired fetal growth: a nation-wide study with complete follow-up. Acta Obstet Gynecol Scand 86: 266-275.

7. Kuebler U, Linnebank M, Semmler A, Stoffel-Wagner B, La Marca R, et al. (2013) Plasma homocysteine levels increase following stress in older but not younger men. Psycho neuro endocrinology 38: 1381-1387.

8. de Oliveira AC, Suchecki D, Cohen S, D'Almeida V (2004) Acute stressor-selective effect on total plasma homocysteine concentration in rats. Pharmacol Biochem Behav 77: 269-273.

9. de Souza FG, Rodrigues MD, Tufik S, Nobrega JN, D'Almeida V, et al. (2006) Acute stressor-selective effects on homocysteine metabolism and oxidative stress parameters in female rats. Pharmacol Biochem Behav 85: 400-407.

10. Jendricko T, Vidović A, Grubisić-llić M, Romić Z, Kovacić Z, et al. (2009) Homocysteine and serum lipids concentration in male war veterans with posttraumatic stress disorder. Prog Neuropsycho pharmacol Biol Psychiatry 33: 134-140.

11. Sawai A, Ohshige K, Kura N, Tochikubo O (2008) Influence of mental stress on the plasma homocysteine level and blood pressure change in young men. Clin Exp Hypertens 30: 233-241.

12. Stoney CM (1999) Plasma homocysteine levels increase in women during psychological stress. Life Sci 64: 2359-2365.

13. Burke G, Robinson K, Refsum H, Stuart B, Drumm J, et al. (1992) Intrauterine growth retardation, perinatal death and maternal homocysteine levels. N Engl J Med 326: 69-70.

14. de Vries JI, Dekker GA, Huijgens PC, Jakobs C, Blomberg BM, et al. (1997) Hyperhomocysteinaemia and protein $S$ deficiency in complicated pregnancies. Br J Obstet Gynaecol 104: 1248-1254.

15. Hogeveen M, Blom HJ, den Heijer M (2012) Maternal homocysteine and small-for-gestational-age offspring: systematic review and meta-analysis. Am J Clin Nutr 95: 130-136.

16. Takimoto H, Mito N, Umegaki K, Ishiwaki A, Kusama K, et al. (2007) Relationship between dietary folate intakes, maternal plasma total homocysteine and B-vitamins during pregnancy and fetal growth in Japan. Eur J Nutr 46: 300-306.

17. Mascarenhas M, Habeebullah S, Sridhar MG (2014) Revisiting the role of first trimester homocysteine as an index of maternal and fetal outcome. J Pregnancy 2014: 1-6.

18. Wouters MG, Boers GH, Blom HJ, Trijbels FJ, Thomas
CM, et al. (1993) Hyperhomocysteinemia: a risk factor in women with unexplained recurrent early pregnancy loss. Fertil Steril 60: 820-825.

19. Nelen WL, Blom HJ, Steegers EA, den Heijer M, Eskes TK, et al. (2000) Hyperhomocysteinemia and recurrent early pregnancy loss: a meta-analysis. Fertil Steril 74: 1196-1199.

20. Vollset SE, Refsum H, Irgens LM, Emblem BM, Tverdal A, et al. (2000) Plasma total homocysteine, pregnancy complications, and adverse pregnancy outcomes: the Hordaland Homocysteine study. Am J Clin Nutr 71: 962-968.

21. Nurk E, Tell GS, Refsum H, Ueland PM, Vollset SE, et al. (2006) Factor $V$ Leiden, pregnancy complications and adverse outcomes: the Hordaland Homocysteine Study. QJM 99: 289-298.

22. Dekker GA, de Vries JI, Doelitzsch PM, Huijgens PC, von Blomberg BM, et al. (1995) Underlying disorders associated with severe early-onset preeclampsia. Am J Obstet Gynecol 173: 1042-1048.

23. Hamilton M (1959) The assessment of anxiety states by rating. $\mathrm{Br} \mathrm{J}$ Med Psychol 32: 50-55.

24. Hamilton M (1960) A rating scale for depression. J Neurol Neurosurg Psychiatry 23: 56-62.

25. DiPietro JA, Costigan KA, Nelson P, Gurewitsch ED, Laudenslager ML, et al. (2008) Fetal responses to induced maternal relaxation during pregnancy. Biol Psychol 77: 11-19.

26. Dipietro JA (2012) Maternal stress in pregnancy: considerations for fetal development. J Adolesc Health 51: S3-S8.

27. Duan H, Yuan Y, Zhang L, Qin S, Zhang K, et al. (2013) Chronic stress exposure decreases the cortisol awakening response in healthy young men. Stress 16: 630-637.

28. Chengfeng S, Wei L, Xinxing W, Lei W, Rui Z, et al. (2014) Hyperhomocysteinemia is a result, rather than a cause, of depression under chronic stress. PLoS One 9: e106625.

29. Tousoulis D, Antoniades C, Marinou K, Vasiliadou C, Bouras $\mathrm{G}$, et al. (2008) Methionine-loading rapidly impairs endothelial function, by mechanisms independent of endothelin-1: evidence for an association of fasting total homocysteine with plasma endothelin-1 levels. J Am Coll Nutr 27: 379-386.

30. Moat SJ, McDowell IF (2005) Homocysteine and endothelial function in human studies. Semin Vasc 5: 172-182.

31. Glowinska B, Urban M, Koput A, Galar M (2003) New atherosclerosis risk factors in obese, hypertensive and diabetic children and adolescents. Atherosclerosis 167: 275-286.

32. Nygård $O$, Vollset $S E$, Refsum $H$, Stensvold I, Tverdal $A$, et al. (1995) Total plasma homocysteine and cardiovascular risk profile. The Hordaland Homocysteine Study. JAMA 274: 1526-1533.

33. Steegers EA, von Dadelszen $P$, Duvekot JJ, Pijnenborg R (2010) Pre-eclampsia. Lancet 376: 631-644.

34. Kaufmann P, Black S, Huppertz B (2003) Endovascular trophoblast invasion: implications for the pathogenesis of intrauterine growth retardation and preeclampsia. Biol Reprod 69: 1-7.

35. Mccaddon A, Regland B (2006) Homocysteine and cognition-no longer a hypothesis? Med Hypotheses 66: 682-683.

36. Blaise SA, Nedelec E, Schroeder H, Alberto JM, Bossen- 
meyer-Pourie C, et al. (2007) Gestational vitamin B deficiency leads to homocysteine-associated brain apoptosis and alters neurobehavioral development in rats. Am J Pathol 170: 667-679.

37. Baydas G, Koz ST, Tuzcu M, Etem E, Nedzvetsky VS, et al. (2007) Melatonin inhibits oxidative stress and apoptosis in fetal brains of hyperhomocysteinemic rat dams. J Pineal Res 43: 225-231.
38. Lipton SA, Kim WK, Choi YB, Kumar S, D'emilia DM, et al. (1997) Neurotoxicity associated with dual actions of homocysteine at the N-methyl-D-aspartate receptor. Proc Natl Acad Sci U S A 94: 5923-5928.

39. Gaifullina AS, Yakovlev AV, Mustafina AN, Weiger TM, Hermann A, et al. (2016) Homocysteine augments BK channel activity and decreases exocytosis of secretory granules in rat GH3 cells. FEBS Lett 590: 3375-3384. 